\title{
ГЕОГРАФИЧЕСКОЕ РАСПРЕДЕЛЕНИЕ ПРОБНЫХ ПЛОЩАДЕЙ БЕРЕЗНЯКОВ СЕВЕРНОЙ ЕВРАЗИИ
}

П.М. Мазуркин, д-р техн, наук, проф., акад. РАЕ и РАЕН, член Европейской Академии Естествознания,

Марийский государственный технический университет, г. Йошкар-Ола

Любое измерение [1], проведенное по учтенным параметрам (количественно выраженным факторам) березняка, свойства которого признаются ныне через пробные площади, дает «срез» всей системы взаимодействий между факторами. Множество измерений, как срезы во времени, дает картину функционирования или популяционную динамику.

Этот эффект мы назвали экосистемной суперпозицией. Исходя из принципа дополнительности в геоботанике [2] под суперпозицией (от лат. super - над и position - положение, расположение) понимается общность изучения пробных площадей, измеренных разными авторами в разные годы, а также возможность раздельного изучения факторных отношений.

Тогда, за период измерений всех пробных площадей по всем породам Северной Евразии с 1927 по 1999 годы, то есть за 72 года, дает пространственно-временную частную цифровую модель поведения 476 березняков. Эту цифровую модель по нашей технологии идентификации $[3,4]$ можно превратить в факторные связи в виде биотехнических закономерностей.

Отдельное рассмотрение влияния восточной долготы $\beta$ на северную широту $\alpha$ по структуре формулы $\alpha=f(\beta)$ дает наглядное картографическое представление о распределении пробных площадей березы.

Таблица 1 В таблице 1 приведен фрагмент по банку дан-

Географические

параметры пробных площадей

\begin{tabular}{|r|c|c|}
\hline $\begin{array}{c}\text { № } \\
\text { ח/п }\end{array}$ & $\begin{array}{c}\text { Широта } \\
\alpha, \text { град }\end{array}$ & $\begin{array}{c}\text { Долгота } \\
\beta, \text { град }\end{array}$ \\
\hline 1 & 61.001 & 45.967 \\
\hline 2 & 59.667 & 11.5 \\
\hline 3 & 52.483 & 0.25 \\
\hline 4 & 52.483 & 0.25 \\
\hline 5 & 52.483 & 0.25 \\
\hline$\ldots$ & $\ldots$ & $\ldots$ \\
\hline 472 & 43.217 & 142.45 \\
\hline 473 & 43 & 144 \\
\hline 474 & 34 & 135.5 \\
\hline 475 & 41 & 48 \\
\hline 476 & 41 & 48 \\
\hline \multicolumn{2}{|c|}{} \\
\end{tabular}
ных проф. В.А. Усольцева [1].

Сравнение числовых значений $\alpha$ и $\beta$ по двум столбцам показало, что из 476 пробных площадей восемь из них не имеют значений по одному фактору. Такие строки исключили из массива данных.

Сортировка данных. Сопоставление 468 полных строк таблицы 1 показало, что, из-за округления геодезических координат, появляются пары так называемых «аномальных» точек на координатной сетке $(\beta, \alpha)$. Чаще всего широта и долгота отмечены в банке данных [1] в целых градусах. На одной и той же долготе, при значительно далеко расположенных по широте пробных площадях, образуется вертикальный рой точек (рис. 1) Эти аномалии не 
могут быть смоделированы из-за того, что у всего этого роя точек одна и та же абсцисса. Такие крайние по показателю $\alpha$ точки удалили.

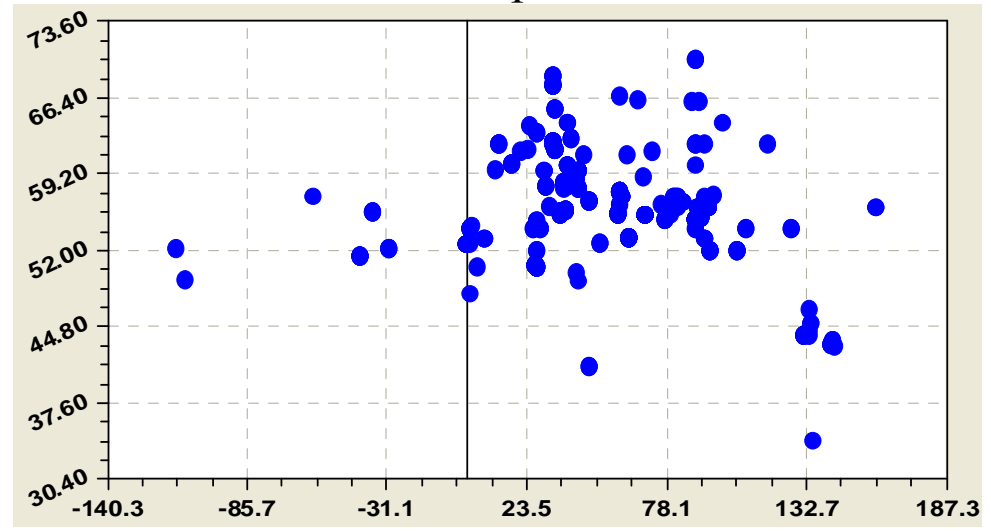

Рис. 1. Распределение 468 пробных площадей березы вдоль Северной Евразии (абсцисса восточная долгота $\beta$, ордината - северная широта $\alpha$ )

После исключения из выборки точек на долготах $28,34,40,44,48$ и 90 градусов осталось 399 пробных площадей или 85,3 \%. Потери географической информации в будущем не будет, если координаты пробных площадей измеряются с погрешностью 0,000001 градуса $(1,1 \mathrm{~m})$.

Модель. На рисунке 2 графически показана последовательность моделирования идентификацией по методике [3, 4].
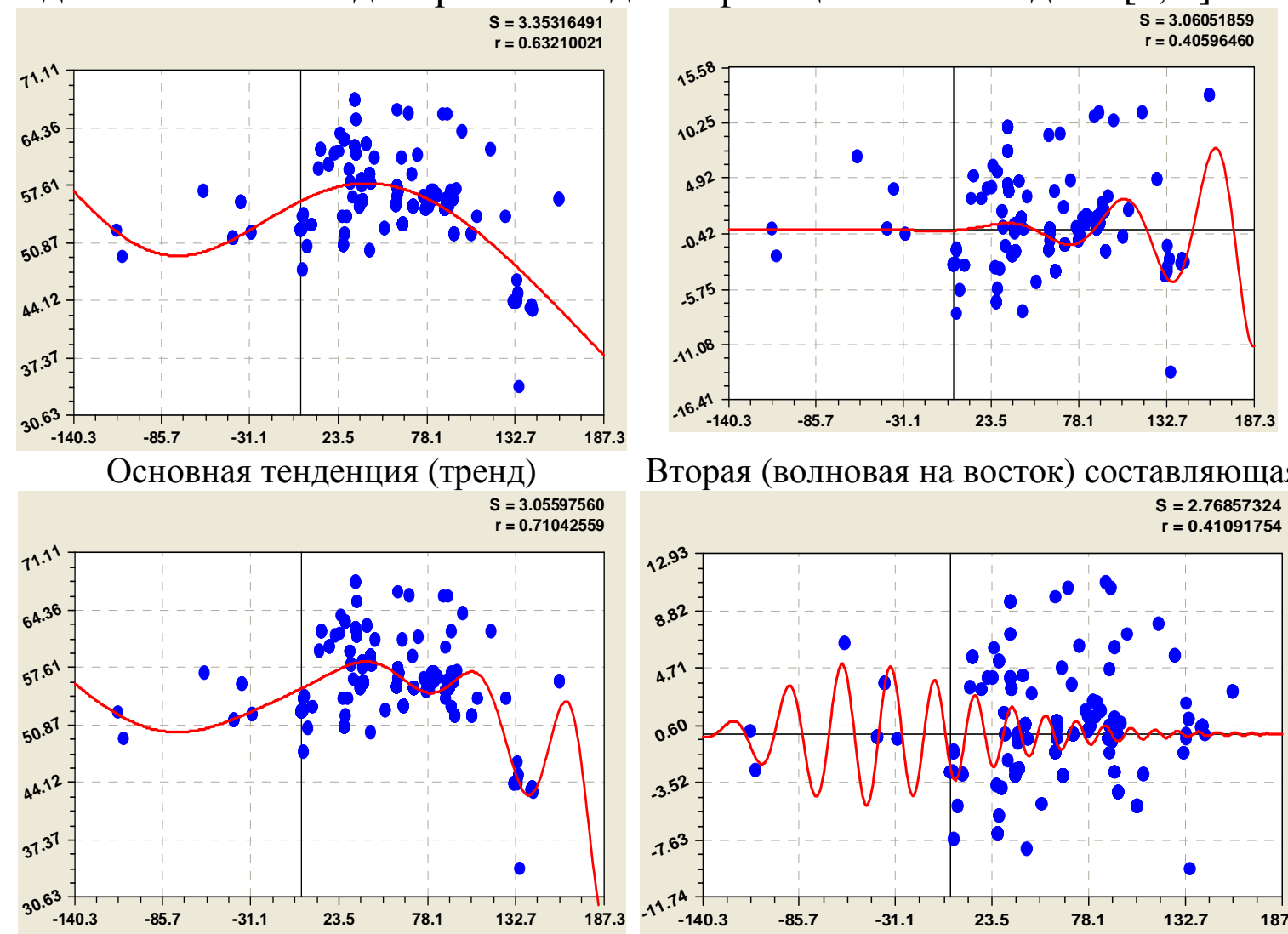

Вторая (волновая на восток) составляющая

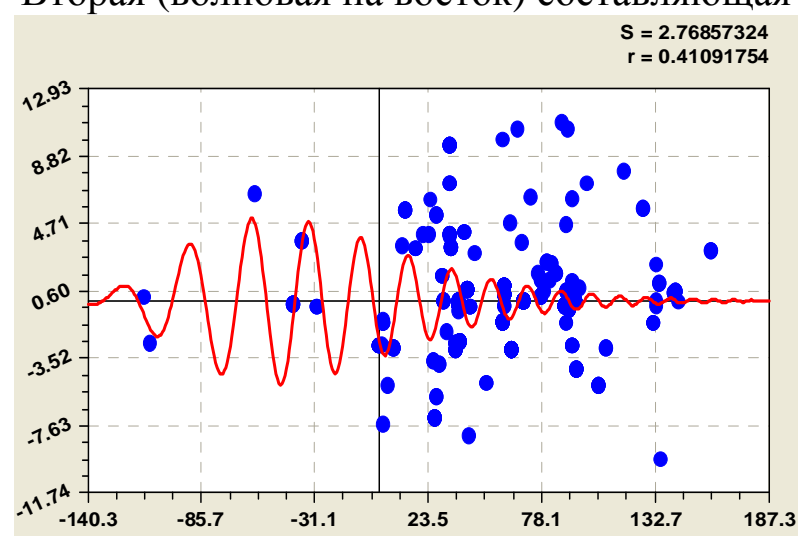

Совместно первая и вторая составляющиеТретья (волновая на Европе) составляющая

Рис. 2. Последовательность получения конструкции математической модели (1)

Были получены две волны (рис. 2), имеющие коэффициент корреляции выше 0,4, расположение которых имеет конкретный смысл. Восточная волна с нарастающей амплитудой показывает разбегание пробных площадей в основном от Урала к Тихому океану, а западная волна оказалась по 
амплитуде замкнутой из-за антропогенного влияния на популяцию березняков. Полвека леса Восточной Европы оставались отрезанными от лесов Западной Европы. Граница «железного занавеса» протяженностью 3000 км определила эти две волны у 399 пробных площадей березняков Евразии.

Волновое размещение пробных площадей. Влияние долготы на широту $\beta \rightarrow \alpha$, то есть географическое распределение пробных площадей березы на территории Северной Евразии, не хаотичное, а четко имеет тенденцию и колебательно закономерное, как это видно из рисунка 3.

$$
\begin{aligned}
S & =2.81203147 \\
r & =0.76974125
\end{aligned}
$$

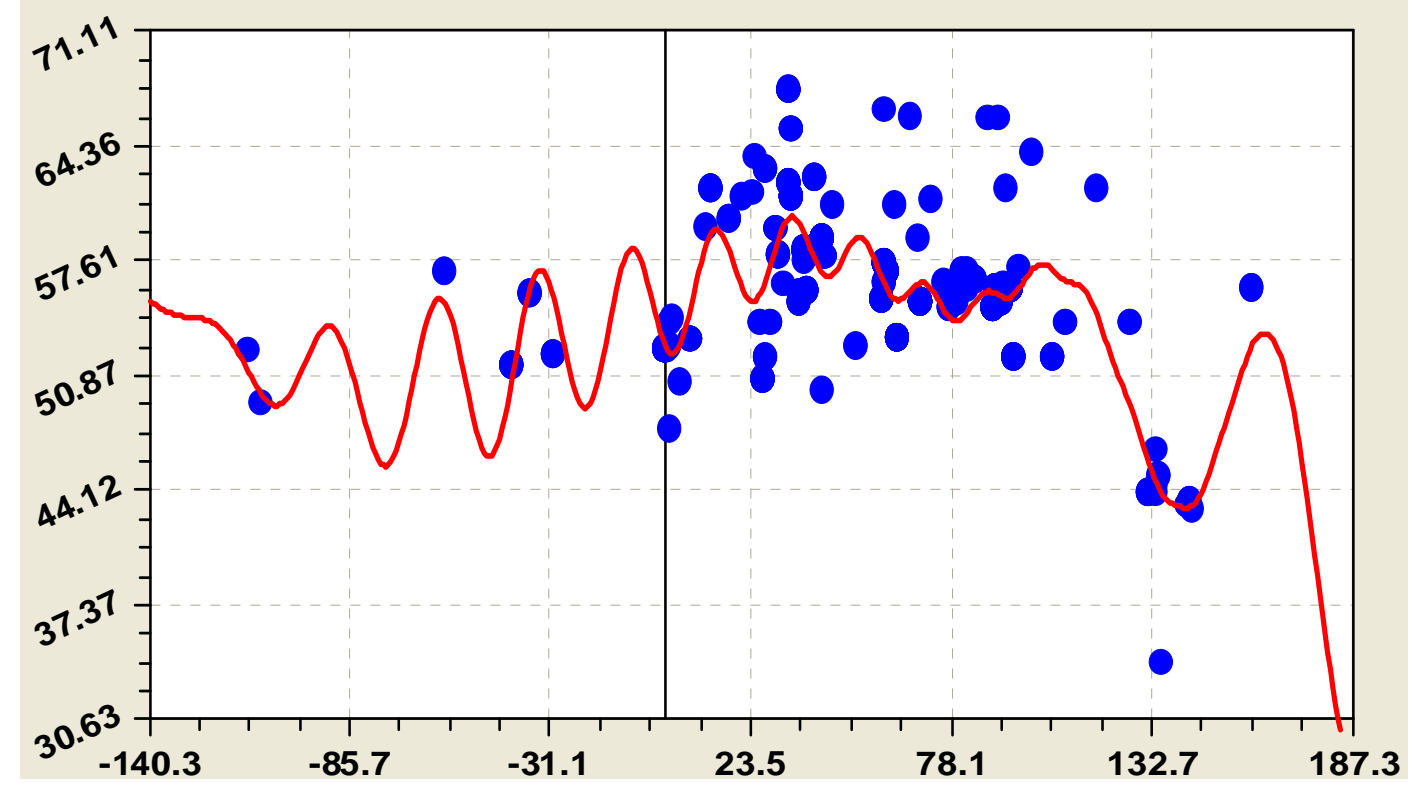

Рис. 3. Модель (1) географического распределения пробных площадей березы

По 399 точкам координат была получена четырехчленная модель:

$$
\begin{aligned}
& \alpha=\alpha_{1}+\alpha_{2}+\alpha_{3}+\alpha_{4}, \\
& \beta^{\prime}=\beta+180, \alpha_{1}=59,72234 \exp \left(-8,54851 \cdot 10^{-5} \beta^{\prime 1,98838}\right), \\
& \alpha_{2}=5,81707 \cdot 10^{-5} \beta^{\prime 3,07781} \exp \left(-0,011893 \beta^{\prime 1,01357}\right), \alpha_{3}=A_{1} \cos \left(\pi \beta^{\prime} / p_{1}+0,10381\right), \\
& A_{1}=3,09751 \cdot 10^{-13} \beta^{\prime 5,30470}, p_{1}=61,67570-0,00075400 \beta^{1,73150}, \\
& \alpha_{4}=A_{2} \cos \left(\pi \beta^{\prime} / p_{2}+3,00076\right), A_{2}=1,28921 \cdot 10^{-11} \beta^{\prime, 722663} \exp \left(-0,12713 \beta^{\prime 0,86276}\right), \\
& p_{2}=18,83449-0,0033910 \beta^{\prime 1,34275},
\end{aligned}
$$

где $\beta$ - восточная долгота по Гринвичу, $\beta^{\prime}$ - долгота в модели (1).

Общая закономерность (1) с двумя волнами (рис. 3) доказывает эффект коррелятивной вариации Ч. Дарвина, по параметру северной широты относительно восточной долготы, с коэффициентом корреляции 0,7697.

Асимметричные вейвлет-сигналы. Каждая очередная волна возмущения сообщества березняков на сетке геодезических координат является сигналом, который научным работникам нужно расшифровать и понять поведение рассматриваемого кластера пробных площадей. 
Эти волновые сигналы по своим концам по оси долготы имеют четкие границы в виде провинций и других биогеоценотических элементов.

Из-за малого объема статьи скажем только, что распределение лесных земельных участков по площади имеет четкий фрактальный характер.

Методика выявления фрактальных сигналов. Из-за низкой точности геодезических координат из [1] вначале исключили наблюдения, аномально расположенные на одной долготе вдоль широты по обеим сторонам оси абсцисс. Примем погрешность измерений $\pm 5^{\prime}$ или $1 / 12^{\circ}$ (расстояние 10-11 км). Тогда из остатков после 12-ого члена модели (2) исключать можно географические точки с широтой, находящейся в пределах $\pm 0,08^{\circ}$.

Затем выявляются тенденции (не волновые составляющие), а по остаткам в программной среде CurveExpert-1.40 - составляющие колебательного возмущения березняков на поверхности суши Земли. Но все члены общей модели без исключения являются сигналами для ученых.

Вейвлет-сигналы. В таблице 2 даны параметры некоторых фракталов из общей математической модели (2), включающей 48 членов.

Первые два члена - это тенденции - длинные волны, у которых полупериод во много раз превышает измеренный интервал долготы.

Таблица 2

Параметры модели широты от долготы пробных площадей березняков

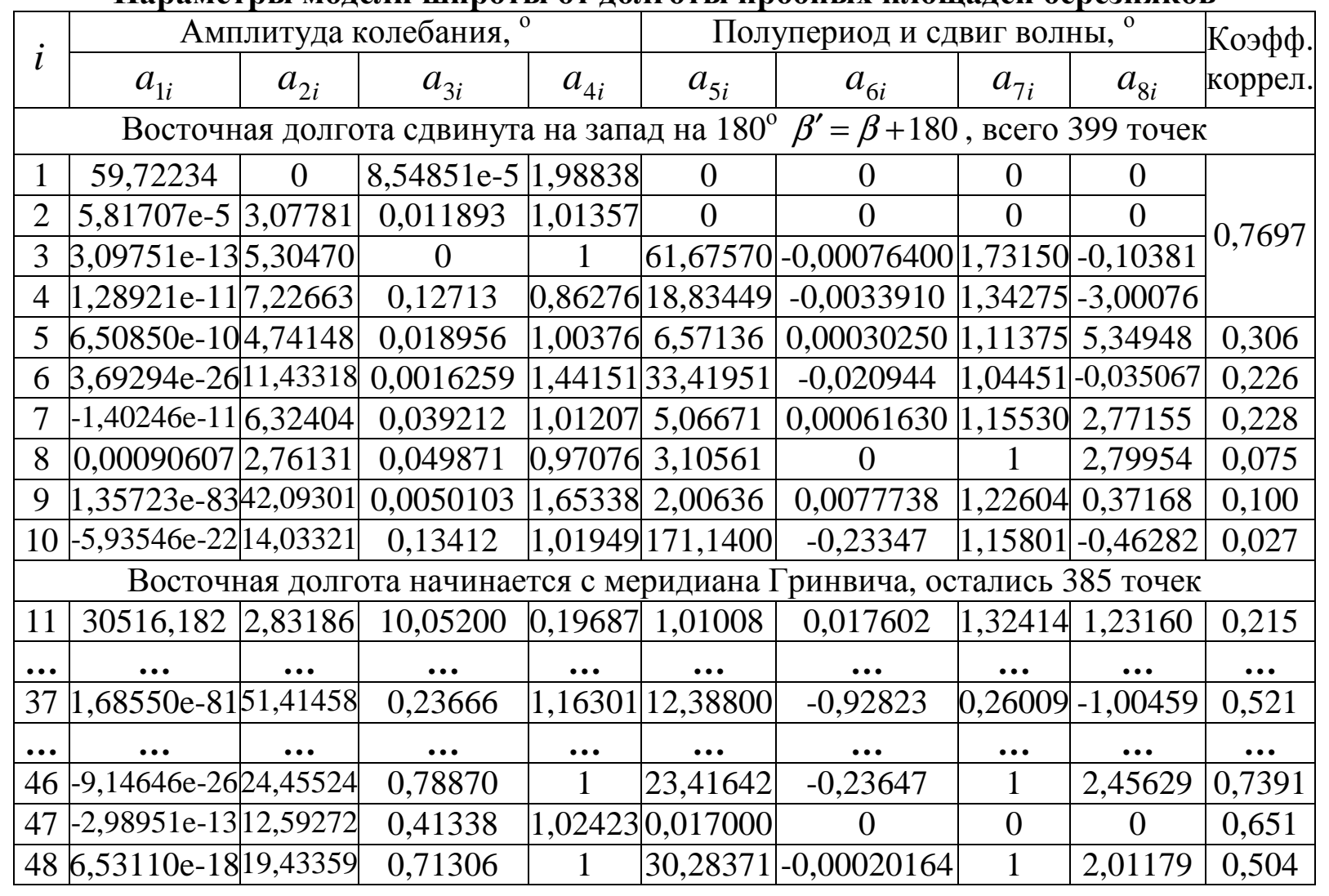

Фрактальность географического распределения березняков доказывается общей волновой закономерностью (табл. 2) вида 


$$
y=\sum_{i=1}^{m} y_{i}, y_{i}=a_{1 i} x^{a_{2 i}} \exp \left(-a_{3 i} x^{a_{4 i}}\right) \cos \left(\pi x /\left(a_{5 i}+a_{6 i} x^{a_{7 i}}\right)-a_{8 i}\right),
$$

где $i$ - порядковый номер составляющей (уровень фрактала) волновой модели (2), причем каждый член этой модели (2) представляет собой обособленный асимметричный вейвлет-сигнал, который нужно расшифровать и эвристически пояснить; $m$ - общее количество членов в функции (2).

Долготные ареалы распространения березы по пробным площадям характеризуются волновыми членами модели (2), что видно из рисунка 4.
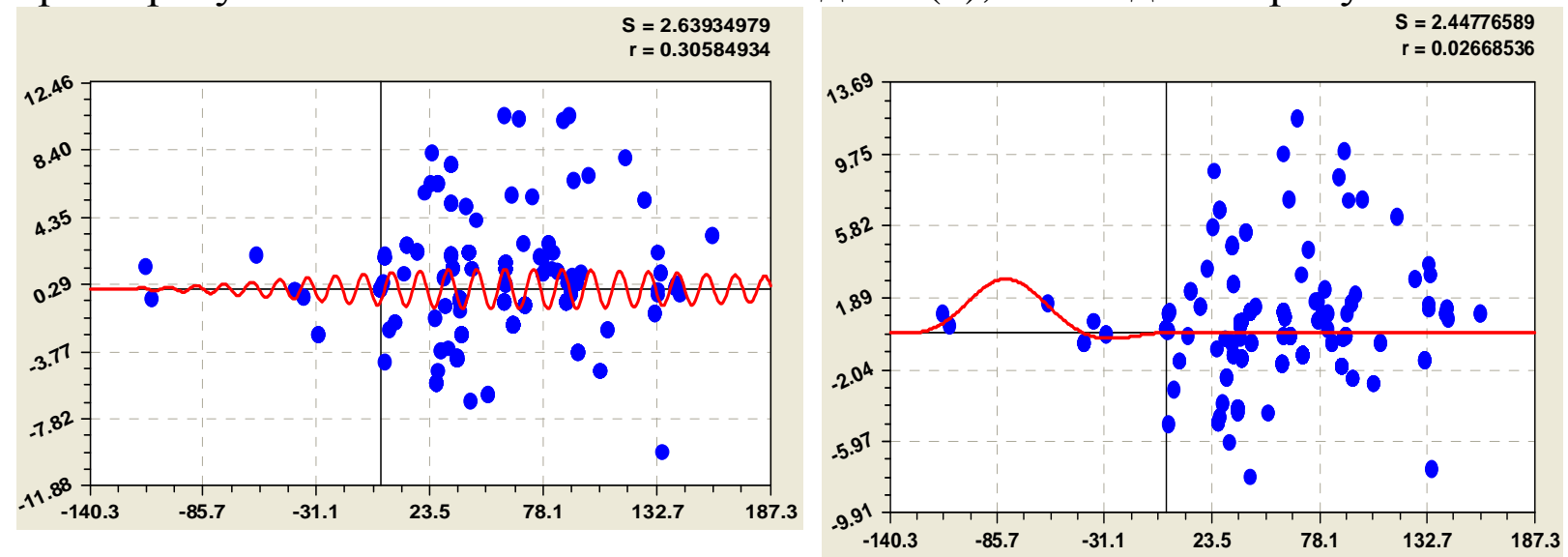

5-й член (2). От Атлантики к Тихому океану

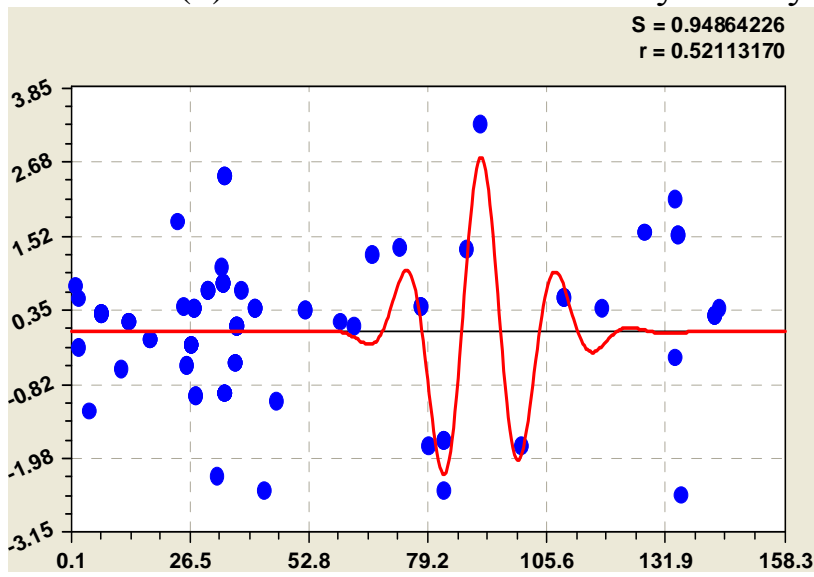

37. Четкий вейвлет-сигнал Зауралья

10. Завершение влияния Атлантики

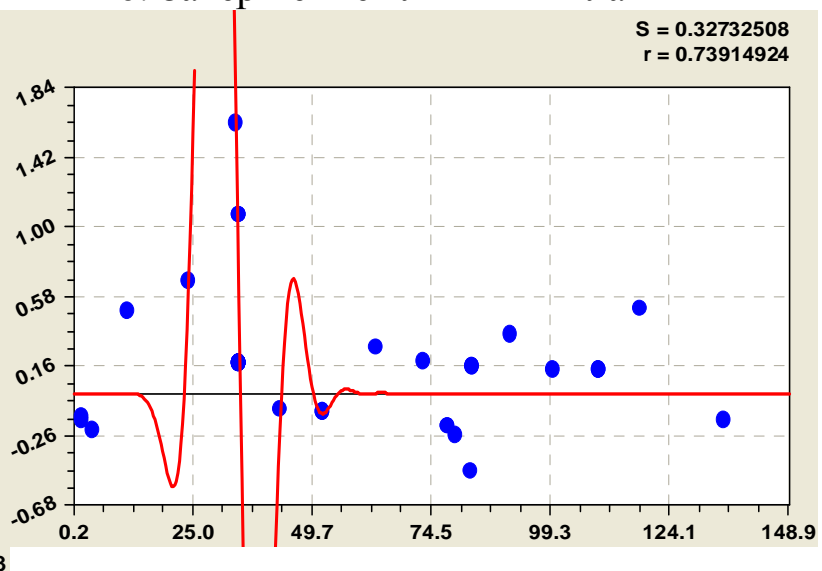

46. Сигнал на Восточной Европе

Рис. 4. Графики членов модели (2) распределения пробных площадей березняков

Каждый член модели (2) имеет свое биогеоценотическое объяснение.

Первый пример на рисунке 4 показывает сквозное колебание всех 399 пробных площадей березняков от Атлантического до Тихого океана и его островов с лесами. При этом 10-я составляющая модели (2) показывает изоляцию кластера березняков на островах Атлантическим океаном.

Дальше были исключены 14 точек с отрицательными долготами от Гринвича при максимальном остатке северной широты менее $0,82^{\circ}$.

По данным (табл. 2) параметров модели 37-й член дает четкий график вейвлета с границами в интервале восточной долготы, начиная от 60 до $130^{\circ}$. По-видимому, этот интервал характеризует азиатскую часть березня- 
ков России. При этом вейвлетом называется математическая функция, у которой площади частей графика над и под осью абсцисс примерно равны. Максимальная амплитуда возмущения находится в интервале северной широты примерно $3,2+2,6=5,8^{\circ}$, то есть около $5,8 \times 40000 / 360=645$ км.

В группе березняков запада России и Восточной Европы по 46-му графику на рисунке 4 происходит сигнал с амплитудой в два градуса (220 Км).

Внимательный анализ колебательных возмущений позволит дать прогнозы о закладке новых пробных площадей березняков Северной Евразии.

Далее кратко рассмотрим возможность оценки каждого сигнала (кластера пробных площадей березняков) по значениям показателя идентификации, автоматически выдаваемого программной средой CurveExpert.

Критерий идентификации $K$ (табл. 3) показывает снижение суммы квадратов отклонений у фактических значений наблюдений от среднестатистической кривой по формуле (2) сигнала.

Таблица 3

Изменение критерия идентификации и влияния составляющей модели (2)

\begin{tabular}{|c|c|c|c|c|c|c|c|c|c|c|c|}
\hline \multirow[b]{2}{*}{$i$} & \multicolumn{5}{|c|}{ Статистические показатели } & \multirow[b]{2}{*}{$i$} & \multicolumn{5}{|c|}{ Статистические показатели } \\
\hline & $N$ & K & $\Delta K$ & $100 \Delta K / K$ & $k_{c \kappa}$ & & $N$ & $K$ & $\Delta K$ & $100 \Delta K / K$ & $k_{c k}$ \\
\hline 0 & 399 & $1,26 \mathrm{e} 14$ & $1,26 \mathrm{e} 14$ & $9,94 \mathrm{e} 9$ & 0,0 & 25 & 189 & 542,0 & 48,7 & 8,99 & 0,0 \\
\hline 1 & 399 & $1,27 \mathrm{e} 6$ & $1,26 \mathrm{e} 06$ & $2,86 \mathrm{e} 4$ & 0,0 & 26 & 189 & 477,7 & 64,3 & 13,46 & 0,0 \\
\hline 2 & 399 & 4407,5 & 718,6 & 19,48 & 0,0 & 27 & 186 & 423,5 & 54,2 & 12,80 & 1,6 \\
\hline 3 & 399 & 3688,9 & 684,1 & 22,77 & 0,0 & 28 & 179 & 387,0 & 36,5 & 9,43 & 0,0 \\
\hline 4 & 399 & 3004,8 & 281 & 10,32 & 0,0 & 29 & 179 & 319,5 & 67,5 & 21,13 & 0,0 \\
\hline 5 & 399 & 2723,8 & 152,7 & 5,94 & 0,0 & 30 & 174 & 263,5 & 56 & 21,25 & 0,0 \\
\hline 6 & 399 & 2571,1 & 141,5 & 5,82 & 0,0 & 31 & 151 & 229,2 & 34,3 & 14,97 & 0,0 \\
\hline 7 & 399 & 2429,6 & 31,8 & 1,33 & 0,0 & 32 & 139 & 222,0 & 7,2 & 3,24 & 0,0 \\
\hline 8 & 399 & 2397,8 & 51,7 & 2,20 & 0,0 & 33 & 131 & 175,5 & 46,5 & 26,50 & 0,0 \\
\hline 9 & 399 & 2346,1 & 3,3 & 0,14 & 0,0 & 34 & 123 & 148,8 & 26,7 & 17,94 & 0,0 \\
\hline 10 & 399 & 2342,8 & 113,2 & 5,08 & 0,0 & 35 & 112 & 130,9 & 17,9 & 13,67 & 0,0 \\
\hline 11 & 385 & 2229,6 & 570 & 34,35 & 3,6 & 36 & 110 & 112,1 & 18,8 & 16,77 & 0,0 \\
\hline 12 & 385 & 1659,6 & 205,7 & 14,15 & 0,0 & 37 & 98 & 80,8 & 31,3 & 38,74 & 0,0 \\
\hline 13 & 358 & 1453,9 & 148,2 & 11,35 & 0,0 & 38 & 98 & 65,2 & 15,6 & 23,93 & 0,0 \\
\hline 14 & 358 & 1305,7 & 117,7 & 9,91 & 0,0 & 39 & 94 & 52,6 & 12,6 & 23,95 & 0,0 \\
\hline 15 & 358 & 1188,0 & 140,7 & 13,43 & 0,0 & 40 & 85 & 43,0 & 9,6 & 22,33 & 0,0 \\
\hline 16 & 358 & 1047,3 & 99,4 & 10,49 & 0,0 & 41 & 71 & 38,8 & 4,2 & 10,82 & 0,0 \\
\hline 17 & 358 & 947,9 & 117,6 & 14,16 & 0,0 & 42 & 62 & 33,5 & 5,3 & 15,82 & 0,1 \\
\hline 18 & 335 & 830,3 & 52,8 & 6,79 & 0,0 & 43 & 57 & 31,5 & 2 & 6,35 & 0,0 \\
\hline 19 & 335 & 777,5 & 22,6 & 2,99 & 0,0 & 44 & 46 & 13,8 & 17,7 & 128,26 & 0,0 \\
\hline 20 & 321 & 754,9 & 36,6 & 5,10 & 9,8 & 45 & 42 & 11,5 & 2,3 & 20,00 & 0,1 \\
\hline 21 & 254 & 718,3 & 58,7 & 8,90 & 0,8 & 46 & 36 & 3,0 & 8,5 & 283,33 & 0,0 \\
\hline 22 & 213 & 659,6 & 36,7 & 5,89 & 0,3 & 47 & 18 & 1,7 & 1,3 & 76,47 & 0,0 \\
\hline 23 & 212 & 622,9 & 32,2 & 5,45 & 0,1 & 48 & 18 & 1,1 & 0,6 & 54,55 & 0,0 \\
\hline 24 & 189 & 590,7 & 718,6 & 19,48 & 0,6 & & & & & & \\
\hline
\end{tabular}

Примечание. Номер $i=0$ дается среднему арифметическому от всей выборки. 
Разница $\Delta K_{i}=K_{i-1}-K_{i}$ от $i-1$ предыдущей волны для изучаемого сигнала $i$ дает критерий влияния члена модели на показатель $\alpha$. Относительный критерий сигнала определится из выражения $100 \Delta K / K$. Скачок $k_{c \kappa}$ критерия идентификации образуется при исключении наблюдений. Мощность статистической выборки по количеству членов $N$ уменьшается.

Среднее арифметическое, в нашем случае $\bar{\alpha}=56,15461^{\circ}$, и его употребляют биологи и лесоводы. Оно дает горизонтальную линию с коэффициентом корреляции, равным нулю. Этот показатель является только неким начальным сигналом, сравниваемым с составляющими модели (2). При этом из данных таблицы 2 видно, что при $i=0$ и $i=1$ критерий идентификации имеет очень большие значения. Поэтому применение простых одночленных уравнений для идентификации дает большие погрешности.

Влияние номера составляющей на статистические показатели идентификации по данным таблицы 3 определилось (рис. 5) уравнениями:

$$
\begin{gathered}
N=399,11885 \exp \left(-0,00023712 i^{2,88175}\right)+0,042895 i^{3,78175} \exp \left(-0,10681 i^{1,11295}\right) ; \\
K=4706,9772 \exp \left(-0,078062 i^{1,05057}\right) ; \\
\Delta K=5,65720 \cdot 10^{9} \exp \left(-15,03129 i^{0,073771}\right) \\
K_{\text {отн }}=54,58246 \exp (-0,44415 i)+0,20794 i^{1,34510} \exp \left(-0,00013908 i^{2,24630}\right) .
\end{gathered}
$$
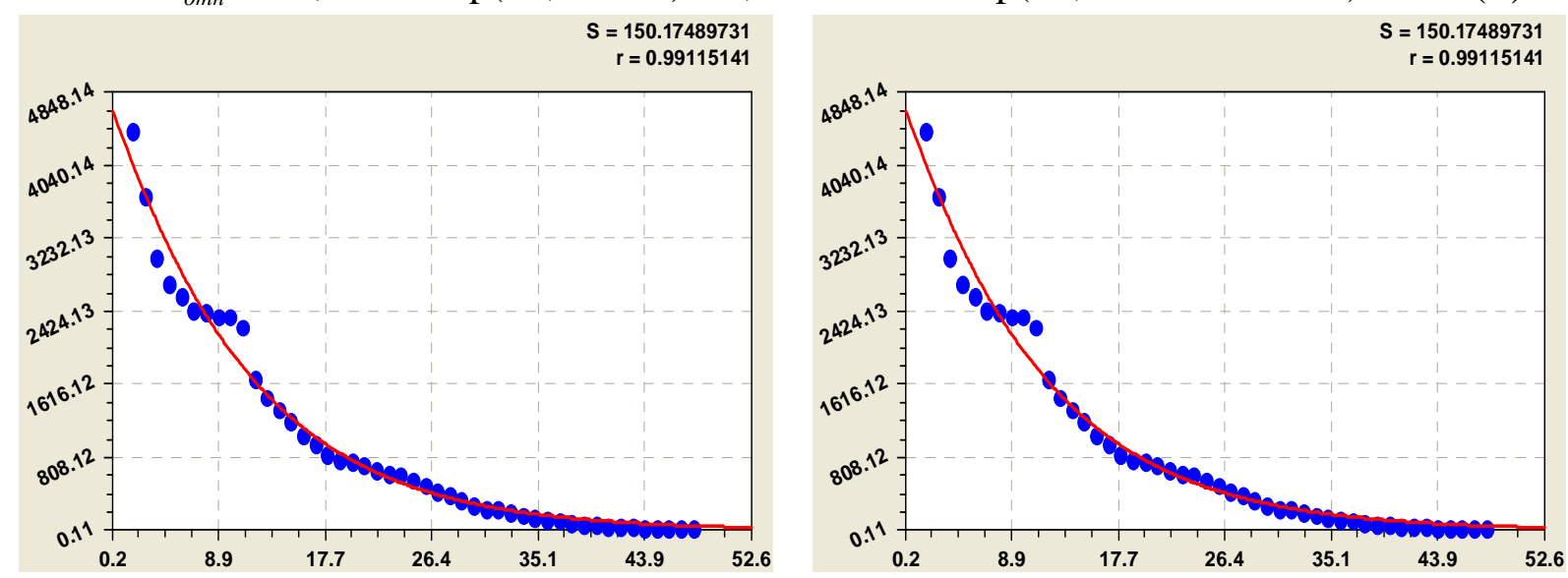

Численность пробных площадей березняков Критерий идентификации (без $i=0$ и $i=1$ )
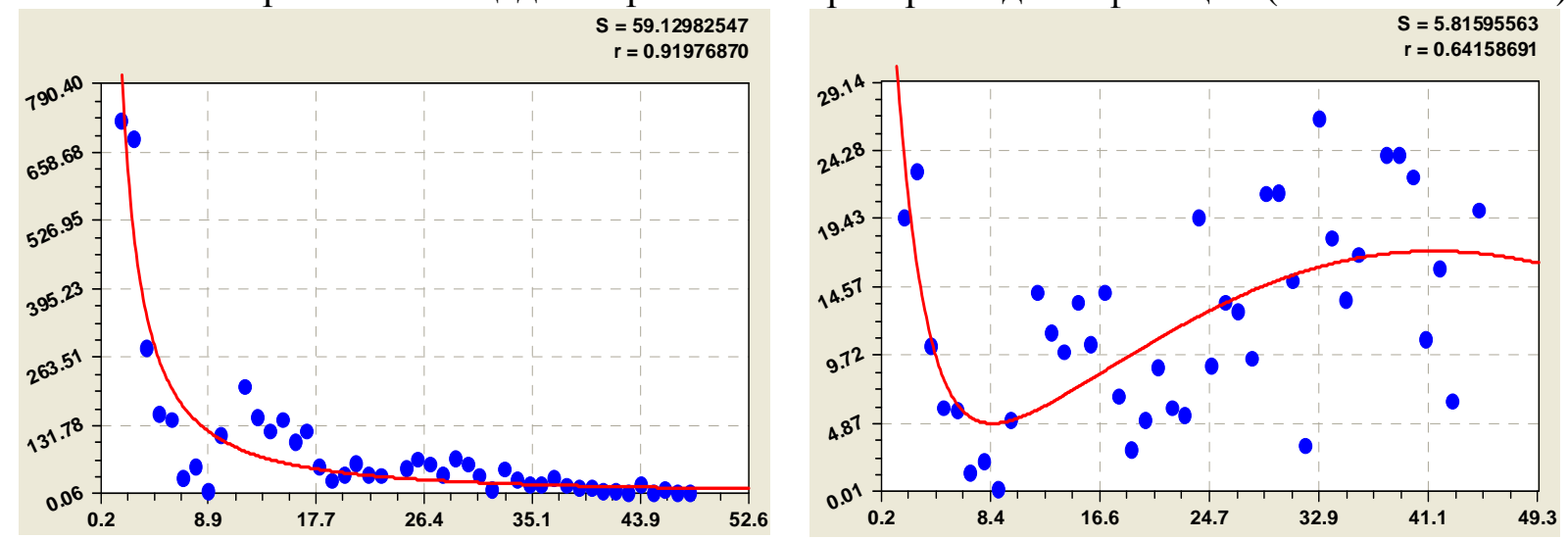

Критерий влияния сигнала (без $0,1,11,24)$ Критерий $100 \Delta K / K(46,44,47,48,37,11)$

Рис. 5. Графики влияния номера членов модели (2) на статистику вейвлет-сигналов 
Необходимость исключения резко отклоняющихся точек объясняется несовершенством программной среды (до 19 параметров модели). Необходима специальная программная среда, позволяющая «потрясти» все составляющие вместе. В нашем случае необходимо ввести в компьютер модель (2) с $48 \times 8=384$ параметрами общего уравнения. А программа для ПЭВМ должна быть разработана для не менее 1000 параметров модели.

На следующем рисунке показан график скачков критерия идентификации, в зависимости от исключения наблюдений, по формуле

$$
k_{c k}=1,76327 \cdot 10^{-113} i^{108,81227} \exp \left(-0,43664 i^{1,66982}\right) \text {. }
$$

$S=1.24623208$ $r=0.58778928$

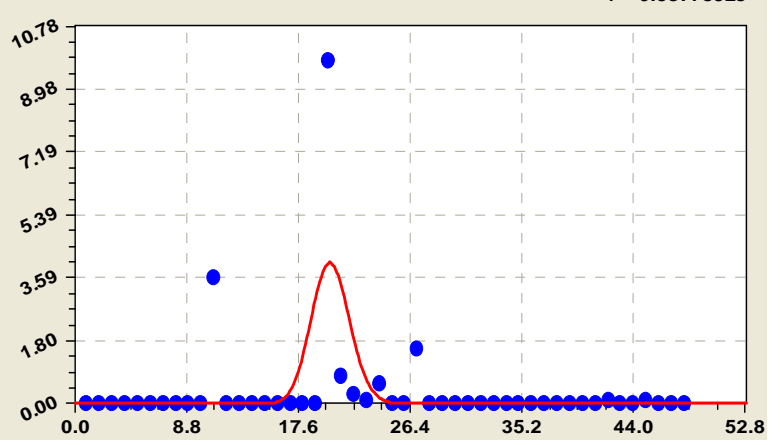

Рис. 6. Влияние номера членов модели (2) на скачок критерия идентификации

Этот скачок $k_{c \kappa}$ также возникает из-за малых возможностей программной среды.

При автоматической структурно-параметрической идентификации общей модели (2) этот и предыдущие четыре критерия будут сверяться после прибавления очередного сигнала (составляющей модели). Тогда появится возможность эвристического (содержательного) объяснения и очередности возникновения вейвлет-сигнала.

Заключение. Проведенное эвристико-статистическое моделирование географического расположения пробных площадей березняков убедительно доказало практическую возможность геостатистики популяций лесных земельных участков, хотя пока и на уровне пробных площадей, при этом даже без учета площади территории и геодезического расположения центров самих березняков на суше Северной Евразии.

\section{Библиографический список}

1. Усольцев, В. А. Фитомасса лесов Северной Евразии: база данных и география / В.А. Усольцев. - Екатеринбург: УрО РАН, 2001. - 706 с.

2. Кучеров, И.Б. О принципе дополнительности в геоботанике. Методологические предпосылки возникновения комплементарных подходов к изучению растительности / И.Б. Кучеров // Журнал общей биологии. 1995. - № 4. Том 56. - С.486-505.

3. Мазуркин, П.М. Математическое моделирование. Идентификация однофакторных статистических закономерностей: Учеб. пос. / П.М. Мазуркин, А.С. Филонов. - Йошкар-Ола: МарГТУ, 2006. - 292 с.

4. Мазуркин, П.М. Факторный анализ таксационных показателей разновозрастного сосняка Сибири / П.М. Мазуркин // Успехи современного естествознания. - 2009. - № 12. - С. 41-48.

Подробно о моделировании www.Google.ru набрать «Мазуркин Петр Матвеевич» 